\title{
AVALIAÇÃO DA VIABILIDADE E DO VIGOR DE SEMENTES DE PEPINO PELO TESTE DE TETRAZÓLIO ${ }^{1}$
}

\author{
LIANA BAPTISTA DE LIMA²; TAIS LEITE F. PINTO³; ANA DIONISIA DA LUZ COELHO NOVEMBRE ${ }^{4}$
}

\begin{abstract}
RESUMO - O objetivo do presente trabalho foi adequar o teste de tetrazólio para avaliação da viabilidade e do vigor das sementes de pepino. As sementes foram hidratadas entre papel a 25 ${ }^{\circ} \mathrm{C}$ e por imersão em água a $40{ }^{\circ} \mathrm{C}$, durante 30 e 60 minutos. Após a hidratação, o tegumento foi removido e, em seguida, os embriões foram imersos em água a $40{ }^{\circ} \mathrm{C}$ por 30 e 60 minutos para retirar a membrana que cobre o embrião. Posteriormente, foi realizada a coloração dos tecidos pela imersão em soluções $0,075 \%$ e $1 \%$ de tetrazólio por 60 minutos a $40{ }^{\circ} \mathrm{C}$ no escuro. Para a avaliação, foram estabelecidas três classes: 1) sementes vigorosas, 2) sementes viáveis não vigorosas e 3) sementes não viáveis. Definido o método, sementes de 12 lotes de pepino foram avaliadas pelos testes de tetrazólio, germinação, emergência das plântulas e envelhecimento acelerado. O teste de tetrazólio pode ser utilizado para avaliar a viabilidade e o vigor de sementes de pepino. Para a condução do teste, as sementes secas devem ser cortadas no lado oposto ao do eixo embrionário, imersas em água a $40{ }^{\circ} \mathrm{C}$ por 60 minutos, para a retirada do tegumento, e por mais 60 minutos a $40{ }^{\circ} \mathrm{C}$, para a remoção da membrana interna, e, em seguida, imersas em solução de tetrazólio $0,075 \%$, a $40{ }^{\circ} \mathrm{C}$ no escuro por 60 minutos.
\end{abstract}

Termos para indexação: Cucumis sativus, análise de sementes, qualidade de semente.

\section{VIABILITY AND VIGOR OF CUCUMBER SEEDS AS EVALUATED BY THE TETRAZOLIUM TEST}

\begin{abstract}
We assessed the usefulness of the tetrazolium test for determining the quality of cucumber seeds (Cucumis sativus). The base of cucumber seeds were scarified opposite the embryonic axis and the seeds hydrated between moist paper at $25{ }^{\circ} \mathrm{C}$ and by immersion in water at $40{ }^{\circ} \mathrm{C}$ for 30 minutes or 60 minutes. After hydration, the tegument was removed and the seeds re-soaked in water at $40{ }^{\circ} \mathrm{C}$ for 30 minutes or 60 minutes to remove the membrane covering the embryo. The embryos were immersed, in the dark, for 60 minutes at $40{ }^{\circ} \mathrm{C}$ in either $0.075 \%(\mathrm{w} / \mathrm{v})$ or $1 \%(\mathrm{w} / \mathrm{v})$ tetrazolium solution and the seeds classified as vigorous, viable but non-vigorous, or unviable. Twelve lots of cucumber seeds were subsequently evaluated by the tetrazolium test and compared to tests based on germination, seedling emergence and accelerated aging. Our results show that the tetrazolium test can be used to evaluate the viability and vigor of cucumber seeds by scarifying the seeds, soaking them in water at $40{ }^{\circ} \mathrm{C}$ for 60 minutes to remove the tegument, removing the embryo membrane by soaking in water for a further 60 minutes at $40{ }^{\circ} \mathrm{C}$ and staining the embryos at $40{ }^{\circ} \mathrm{C}$ by immersing them for 60 minutes, in the dark, in $0.075 \%$ tetrazolium solution.
\end{abstract}

Index terms: Cucumis sativus, seed analysis, seed quality, tetrazolium test, viability.

\footnotetext{
${ }^{1}$ Submetido em 19/05/2009. Aceito para a publicação em 16/10/2009.

${ }^{2}$ Eng. Agr, Dr. Bolsista CNPq Programa DCR/Fundect, Departamento de Biologia UFMS, CP 549, CEP 79070-900, Campo Grande, e-mail: lianablima@gmail.com
}

${ }^{3}$ Eng. Agr, Doutoranda, Departamento de Produção Vegetal, USP/ESALQ, e-mail: tais_leite@yahoo.com

${ }^{4}$ Eng. Agr, Prof. Dr., Departamento de Produção Vegetal, USP/ESALQ, CP 09, CEP 13418-900, Piracicaba, e-mail: adlcnove@esalq.usp.br 


\section{INTRODUÇÃO}

Os testes que fornecem resultados de análise de sementes em período de tempo curto são fundamentais para agilizar as decisões nas diferentes etapas da produção de sementes. Nesse sentido, o teste de tetrazólio tem posição de destaque para algumas culturas, em função do número de informações sobre a viabilidade e o vigor e da possibilidade de diagnosticar os principais problemas que podem afetar a qualidade das sementes (AOSA, 1983; França Neto et al., 1999) fornecendo resultados, de modo geral, em menos de 24 horas (Barros, 1988).

É um teste em que a observação da coloração obtida nas diferentes partes da semente, após a exposição ao sal de tetrazólio, permite determinar a presença, a localização e a natureza das alterações dos tecidos das sementes (AOSA, 1983; França Neto et al., 1999) e classificá-las quanto à viabilidade e, ou, ao vigor.

Assim, a eficiência do teste depende do desenvolvimento de métodos adequados para cada espécie, que visem à obtenção de um padrão de coloração nítido, para que a avaliação e a interpretação da condição de cada semente possam ser realizadas de maneira correta. As etapas para a realização do teste de tetrazólio incluem, normalmente, a hidratação, o preparo, a coloração das sementes e a avaliação.

Recomendações para aplicação desse teste estão descritas para algumas espécies, dentre as quais soja (França Neto et al., 1988, 1999), feijão (Bhering et al., 1996), milho (Dias e Barros, 1995; Chamma e Novembre, 2007), algodão (Vieira e Von Pinho, 1999) e gramíneas forrageiras (Carvalho e Toledo, 1976; Dias e Alves, 2001; Novembre et al., 2006). Para as espécies hortícolas estudos foram realizados para tomate (Santos et al., 2007), abobrinha (Barros et al., 2005) e melancia (Bhering et al., 2005).

Para sementes de pepino pode-se obter alguma informação nas Regras para Análise de Sementes (RAS), incluída de forma generalizada nas indicações para o teste de tetrazólio em sementes de espécies da família Cucurbitaceae (Brasil, 1992). Nesse caso, a recomendação é que as sementes sejam embebidas em água ou entre papel por 6 a 18 horas, submetidas a um corte longitudinal ou transversal através dos cotilédones antes da coloração e mantidas a $30^{\circ} \mathrm{C}$ em solução $1 \%$ de tetrazólio por 6 a 24 horas. Entretanto, alguns autores trabalhando com diversas espécies, verificaram que há possibilidade de utilizar temperaturas superiores a 30
${ }^{\circ} \mathrm{C}$ e períodos de tempo menores para a obtenção da coloração ideal (França Neto et al., 1998; Dias e Barros, 1995; Bhering et al., 1999; Bittencourt e Vieira, 1999; Barros et al., 2005; Bhering et al., 2005; Novembre et al., 2006; Chamma e Novembre, 2007). Além disso, é possível também reduzir a concentração da solução de tetrazólio.

Nesse sentido, é necessário que essas recomendações gerais sejam detalhadas para as sementes de pepino; do mesmo modo, precisam ser definidos os critérios para a interpretação da coloração e para a classificação das sementes quanto à viabilidade e ao vigor.

O objetivo do presente trabalho foi adequar o teste de tetrazólio para avaliação da viabilidade e do vigor das sementes de pepino.

\section{MATERIAL E MÉTODOS}

A pesquisa foi desenvolvida no Laboratório de Sementes do Departamento de Produção Vegetal da Escola Superior de Agricultura Luiz de Queiroz - USP, utilizando sementes de pepino dos cultivares Jóia e Safira, com potenciais fisiológicos distintos.

$\mathrm{Na}$ primeira etapa, sementes de três lotes do cv. Jóia, foram avaliadas inicialmente por meio dos testes de germinação e de envelhecimento acelerado, a fim de obter os resultados da viabilidade e do vigor, respectivamente, a serem empregados como referência para o estudo do teste de tetrazólio.

Para o teste de germinação foram utilizadas 200 sementes divididas em quatro repetições de 50, distribuídas sobre papel umedecido com água, em quantidade equivalente a 2,0 vezes a massa do papel seco, e mantidas em germinador a $25{ }^{\circ} \mathrm{C}$. As avaliações foram efetuadas aos quatro e oito dias após a semeadura (Brasil, 1992) e o resultado expresso em porcentagem de plântulas normais.

No teste de envelhecimento acelerado, 200 sementes foram dispostas em camada única sobre uma tela metálica colocada no interior de caixas plásticas $(11 \mathrm{~cm} \times 11 \mathrm{~cm} \times$ $3 \mathrm{~cm}$ ), contendo $40 \mathrm{~mL}$ de solução saturada de cloreto de sódio. As caixas foram tampadas e mantidas em câmara, tipo BOD, a $41{ }^{\circ} \mathrm{C}$ por 96 horas (Lima e Marcos Filho, 2007). Após esse período, as sementes foram colocadas para germinar conforme descrito para o teste de germinação, com a contagem das plântulas normais realizada no quarto dia após a semeadura. Os resultados foram expressos em porcentagem de plântulas normais. 
Para o teste de tetrazólio, testes preliminares indicaram que o tegumento da semente de pepino impedia a absorção da solução de tetrazólio. Assim, foram pesquisados métodos para a eliminação do tegumento e da membrana que envolve o embrião, utilizando sementes de três lotes do cultivar Jóia. Inicialmente foram avaliados os cortes, testando-se os seguintes procedimentos: semente úmida cortada longitudinalmente através da metade distal dos cotilédones (Brasil, 1992); semente úmida cortada transversalmente através dos cotilédones, um terço a partir da parte basal (Brasil, 1992); semente úmida cortada longitudinalmente pela seção média entre as faces planas da metade distal (Moore, 1972) e semente seca cortada transversalmente na extremidade oposta ao eixo embrionário em porção inferior a $2 / 3$ da área total da semente. Este último foi o mais eficiente para retirar o tegumento e, portanto, o utilizado para o restante da pesquisa. Depois de estabelecido o método para o corte das sementes, dois métodos de hidratação para a retirada do tegumento foram testados: entre papel toalha em germinador a $25{ }^{\circ} \mathrm{C}$ por 16 horas e imersão em água a $40^{\circ} \mathrm{C}$ por 30 e 60 minutos. Completada a hidratação das sementes, o tegumento foi retirado com auxílio de lâmina.

Após a retirada do tegumento, foi necessário retirar a membrana que envolve o embrião e que impede a absorção da solução de tetrazólio. Para tanto, os embriões foram imersos em água a $40{ }^{\circ} \mathrm{C}$ por 30 e 60 minutos (Barros et al., 2005). Decorridos os períodos de imersão, a membrana foi removida com uma pinça, a partir do ponto onde o corte havia sido feito. Em seguida, os embriões foram imersos em solução de 2,3,5 trifenil cloreto de tetrazólio a $1 \%$ e a $0,075 \%$ durante 60 minutos, no escuro a $40{ }^{\circ} \mathrm{C}$. Posteriormente, os embriões foram lavados em água corrente e mantidos em água até a avaliação. Para cada etapa de retirada do embrião, foram utilizadas quatro repetições de 25 sementes de cada lote.

Para a avaliação da viabilidade e do vigor, os embriões foram seccionados longitudinalmente, de forma a separar os dois cotilédones e permitir a observação dos tecidos externos e internos. Assim, as duas metades obtidas foram analisadas quanto à integridade dos tecidos, à localização, extensão e intensidade da coloração e à presença de áreas brancas em relação às áreas essenciais para o desenvolvimento do embrião (plúmula, eixo hipocótilo-radícula e cotilédones). Dessa forma, as cores vermelha brilhante ou rosa brilhante relacionaram-se aos tecidos vivos e vigorosos, a vermelha carmim aos tecidos em deterioração e a branca ou amarelada aos tecidos mortos. Com base nas características observadas e nos padrões indicados por Moore (1972), os embriões foram individualmente classificados em três classes: 1) vigorosos, 2) viáveis e não vigorosos e 3) não viáveis. A descrição das classes e os esquemas representativos estão apresentados na Figura 1, 2 e 3.

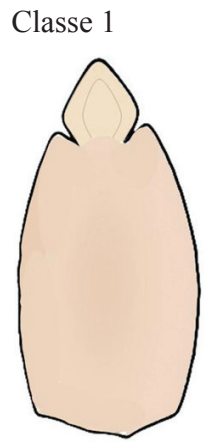

A

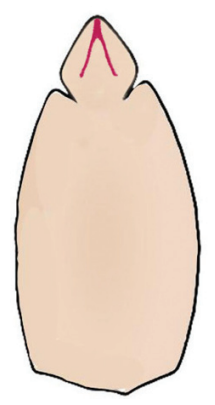

$\mathrm{B}$

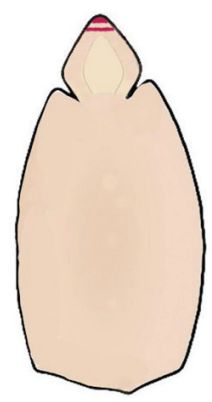

$\mathrm{C}$

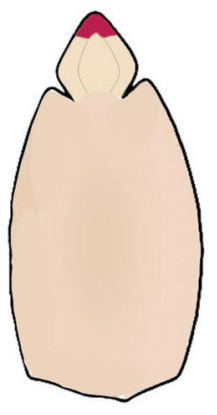

$\mathrm{D}$

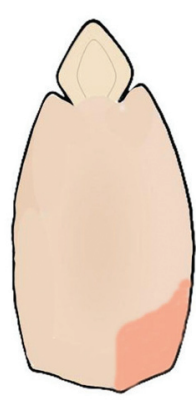

$\mathrm{E}$

FIGURA 1. Representação da classe de sementes vigorosas de pepino (Classe 1). Embriões perfeitos, sem ranhuras ou cortes, com coloração uniforme rosa pálido, tecidos firmes e brilhantes e ausência de áreas descoloridas (a); embriões com coloração rosa intensa ao longo do córtex, mas externamente (b); embriões que apresentam estrias (c) ou manchas (d) na extremidade superior da radícula, sem atingir o eixo embrionário; embriões apresentando manchas brancas ou rosa intenso restritas à extremidade oposta ao eixo embrionário ou superficialmente na parte externa dos cotilédones (e). 


\section{Classe 2}

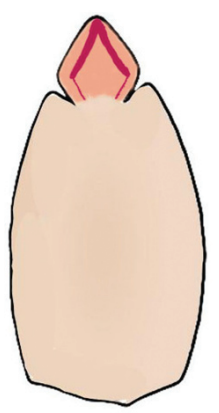

A

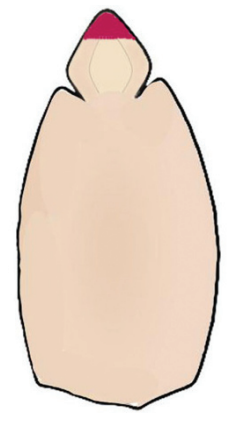

$\mathrm{B}$

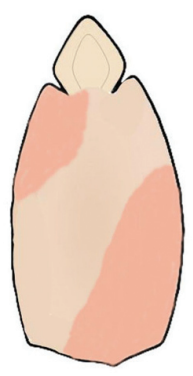

$\mathrm{C}$

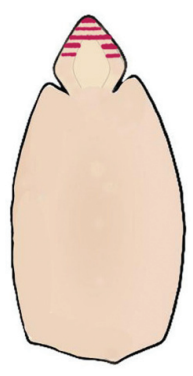

$\mathrm{D}$

FIGURA 2. Representação da classe de sementes viáveis e não vigorosas de pepino (Classe 2). Eixo embrionário de cor rosa, apresentando coloração rosa intensa ou vermelha ao longo e externamente ao córtex (a) ou atingindo apenas a extremidade superior deste e ocupando no máximo 1/3 do eixo (b). Embriões com eixo embrionário sem danos e cotilédones com manchas de cor branca e, ou, rosa intenso e, ou, vermelha em extensão inferior a metade total do embrião, assim como cortes ou anormalidades nos cotilédones também em extensão inferior a metade total do embrião (c). Eixo embrionário apresentando estrias de cor rosa intenso que não atingem o córtex (d).

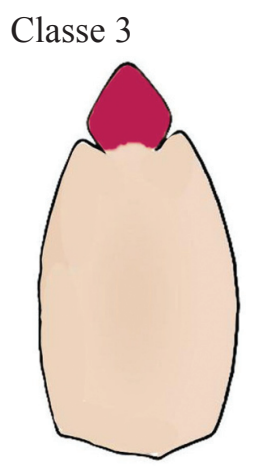

A

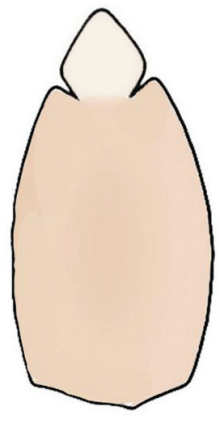

$\mathrm{B}$

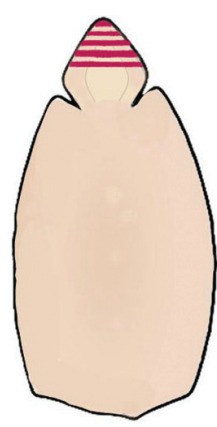

$\mathrm{C}$

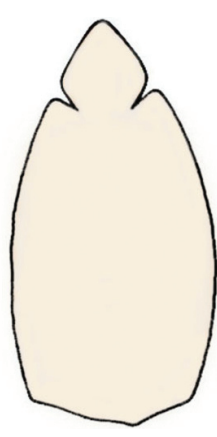

$\mathrm{D}$

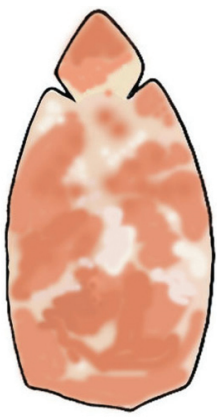

$\mathrm{E}$

FIGURA 3. Representação da classe de sementes não viáveis de pepino (Classe 3). Os embriões apresentam eixo embrionário de cor vermelha carmim (a) ou branca (b) em toda sua extensão ou em mais de 2/3 de sua extensão; eixo embrionário apresentando listras em toda sua extensão ou em mais de $2 / 3$ de sua extensão atingindo a região do córtex (c); embrião de cor branca em toda a sua extensão (d); e embrião com distribuição das cores vermelha, rosa e branca formando um mosaico inclusive no eixo embrionário (e).

Para o cálculo dos resultados de viabilidade, os dados da classe 1 foram somados aos da classe 2 e o resultado final foi comparado com o obtido no teste de germinação. Para o estudo do vigor, foram comparados os resultados da classe 1 com os do teste de envelhecimento acelerado.

Definido o procedimento para realização do teste de tetrazólio, seis lotes do cultivar Jóia (lotes 1 a 6 ) e seis do cultivar Safira (lotes 7 a 12) foram avaliados pelo teste de tetrazólio e foi comparada a eficiência desse teste, para separar os lotes em diferentes níveis de potencial fisiológico, em relação aos testes de germinação, emergência das plântulas e envelhecimento acelerado, constituindo a segunda etapa 
da pesquisa. Os testes de germinação e de envelhecimento acelerado foram realizados segundo descrição anterior. $\mathrm{O}$ teste de emergência das plântulas foi conduzido utilizando bandejas de poliestireno com 200 células, contendo substrato Plantmax ${ }^{\circledR}$, onde foram distribuídas 4 repetições de 50 sementes por lote, as bandejas foram mantidas em ambiente protegido com irrigação diária. A porcentagem de emergência das plântulas foi determinada aos oito dias após semeadura.

Para a análise estatística, foi utilizado o delineamento inteiramente casualizado, com a comparação das médias pelo teste de Tukey a $5 \%$ de probabilidade.

\section{RESULTADOS E DISCUSSÃO}

Dentre os métodos de hidratação testados para a retirada do tegumento, o método em que se utilizou papel umedecido e temperatura de $25{ }^{\circ} \mathrm{C}$ não foi eficiente, pois, após ter transcorrido o período de 16 horas, o tegumento das sementes ainda permanecia aderido, dificultando a sua remoção sem que ocorressem injúrias ao embrião. Por esse motivo, esse método não foi considerado adequado e os dados não foram incluídos na análise estatística. Além do mais, Costa e Marcos Filho (1994) enfatizaram que as primeiras horas de absorção de água pela semente são importantes, pois se relacionam com a intensidade da atividade enzimática e, portanto, com o desenvolvimento de coloração adequada no final do teste.

Por outro lado, a imersão das sementes em água, a 40 ${ }^{\circ} \mathrm{C}$ por 30 e 60 minutos, facilitou a remoção do tegumento. Barros et al. (2005) e Bhering et al. (2005) também verificaram que o método de imersão em água a $40{ }^{\circ} \mathrm{C}$ foi eficiente para a remoção do tegumento das sementes de abobrinha e de melancia. Possivelmente, a utilização de papel umedecido e temperatura de $25{ }^{\circ} \mathrm{C}$, poderiam ser viáveis com o aumento do período de hidratação. No entanto, tendo em vista que o objetivo constante da pesquisa em análise de sementes é o desenvolvimento de testes que forneçam resultados de forma rápida e segura, a utilização de $40{ }^{\circ} \mathrm{C}$ se constitui em alternativa viável, pois contribui para diminuir o período necessário para conclusão do teste. No Brasil, o teste de tetrazólio é amplamente utilizado para avaliação da qualidade das sementes de soja e o período de pré-condicionamento pode ser reduzido de 16 horas para 6 horas com o aumento da temperatura de hidratação de 25 ${ }^{\circ} \mathrm{C}$ para $41{ }^{\circ} \mathrm{C}$ (Costa et al., 1998; Costa et al., 2008).

O método utilizado para a remoção do tegumento e da membrana interferiu nos resultados, uma vez que, quanto menor a aderência dessas partes houve menos danos ao embrião durante a remoção. Assim, dentre outros fatores, o método da remoção do tegumento e da membrana afetou tanto a uniformidade de coloração dos tecidos quanto o desenvolvimento da coloração adequada para a realização de interpretação confiável.

As Regras para Análise de Sementes (Brasil, 1992) indicam o uso de solução $1 \%$ a $30{ }^{\circ} \mathrm{C}$ por 6 a $24 \mathrm{~h}$ para coloração de embriões de sementes de espécies do gênero Cucumis. No presente trabalho, utilizou-se a temperatura de $40{ }^{\circ} \mathrm{C}$ visando diminuir esse período; no entanto, para essa temperatura, a utilização de solução de tetrazólio a 1\% não foi adequada, pois resultou em uma coloração intensa em toda a extensão do embrião, dificultando a visualização, a distinção e a avaliação dos danos. Por esse motivo, o uso de solução de tetrazólio a $1 \%$ não foi considerado eficiente e os resultados não foram incluídos na análise estatística. Já, a utilização da solução de tetrazólio a $0,075 \%$ permitiu a obtenção de coloração uniforme, nítida e suficiente para o exame adequado dos embriões, de acordo com as recomendações de Moore (1972) em, aproximadamente, 60 minutos.

Assim, os resultados da avaliação da viabilidade e do vigor submetidos à análise estatística incluíram os obtidos com a imersão das sementes em água a $40{ }^{\circ} \mathrm{C}$ por 30 ou 60 minutos, para retirada do tegumento, associada à imersão em água a $40{ }^{\circ} \mathrm{C}$ por 30 ou 60 minutos, para retirada da membrana, e a coloração com solução de tetrazólio a $0,075 \%$ por 60 minutos a $40{ }^{\circ} \mathrm{C}$ no escuro.

As Figuras 1, 2 e 3 apresentam, respectivamente, as classes 1 (vigorosas), 2 (viáveis e não vigorosas) e 3 (não viáveis), estabelecidas utilizando como critérios a integridade dos tecidos e a extensão, intensidade e localização das cores vermelha, rosa e branca. A viabilidade é obtida somando os resultados das classes 1 e 2 e o vigor corresponde à classe 1. Para orientar a definição das classes foram considerados os critérios gerais estabelecidos para espécies do gênero Cucumis descritos nas RAS (Brasil, 1992), em que, em sementes viáveis, a área de tecido não colorido, flácido ou necrosado pode atingir, no máximo, $1 / 3$ da extremidade da radícula ou $50 \%$ dos cotilédones na extremidade oposta ao eixo embrionário ou ao longo da borda dos cotilédones.

Os teores de água iniciais das sementes dos lotes $1,2 \mathrm{e}$ 3 do cv. Jóia, foram respectivamente, 6,3, 6,8 e 6,6\%, com uma variação de 0,5 de ponto porcentual entre os lotes. Da mesma forma, após os períodos de embebição para a retirada do tegumento, a diferença de teor de água entre as sementes 
dos lotes foi menor que 2 pontos porcentuais, situando-se entre 22,2 e $23,6 \%$ para o tratamento de 30 minutos e entre 24,4 e $25,4 \%$ para 60 minutos. A ocorrência de diferenças mínimas entre os teores de água dos lotes é considerada ideal para a obtenção de resultados consistentes (Marcos Filho, 2005).

Os resultados da viabilidade de sementes estão apresentados na Tabela 1. A imersão das sementes em água por 60 minutos, para a retirada do tegumento, seguida da imersão por 60 minutos para retirada da membrana foram eficientes. Utilizando esse método, as porcentagens de sementes viáveis dos lotes 1 e 2 foram estatisticamente iguais as dos resultados do teste de germinação. Para o lote 2 a utilização de 60 minutos, para a retirada do tegumento, seguida de imersão por 30 minutos para retirada da membrana também foi eficiente. Para o lote 3, a imersão das sementes por 60 minutos para a retirada do tegumento, seguida de imersão por 30 ou 60 minutos para a retirada da membrana, foram os métodos em que a viabilidade das sementes pelo teste de tetrazólio foi a mais próxima à do teste de germinação, dentre todos os métodos.

TABELA 1. Viabilidade e vigor de sementes de pepino, lotes 1, 2 e 3, cultivar Jóia, avaliados pelos testes de tetrazólio (TZ), imersão das sementes em água por 30 ou 60 minutos, para remoção do tegumento - T (30min T ou $60 \mathrm{~min}$ T), seguida da imersão por 30 ou 60 minutos, para a remoção da membrana - M (30min M ou $60 \mathrm{~min} M$ ), de germinação e de envelhecimento acelerado.

\begin{tabular}{cccc}
\hline \multirow{2}{*}{ Tratamentos } & Lote 1 & Lote 2 & Lote 3 \\
\cline { 2 - 3 } & & Viabilidade (\%) & \\
\hline TZ 30min T + 30min M & $49 \mathrm{~d}^{1}$ & $76 \mathrm{ab}$ & $74 \mathrm{c}$ \\
TZ 30min T + 60min M & $53 \mathrm{~cd}$ & $68 \mathrm{~b}$ & $82 \mathrm{~b}$ \\
TZ 60min T + 30min M & $57 \mathrm{bc}$ & $80 \mathrm{a}$ & $82 \mathrm{~b}$ \\
TZ 60min T + 60min M & $61 \mathrm{ab}$ & $73 \mathrm{ab}$ & $89 \mathrm{a}$ \\
\hline Germinação & $64 \mathrm{a}$ & $82 \mathrm{a}$ & 6,0 \\
\hline C.V. (\%) & 4,9 & 6,8 & Lote 3 \\
\hline Tratamentos & Lote 1 & Lote 2 & $33 \mathrm{c}$ \\
\hline TZ 30min T + 30min M & & Vigor $(\%)$ & $54 \mathrm{~b}$ \\
TZ 30min T + 60min M & $29 \mathrm{c}$ & $50 \mathrm{~b}$ & $52 \mathrm{~b}$ \\
TZ 60min T + 30min M & $22 \mathrm{~d}$ & $31 \mathrm{c}$ & $70 \mathrm{a}$ \\
TZ 60min T + 60min M & $33 \mathrm{c}$ & $48 \mathrm{~b}$ & $77 \mathrm{a}$ \\
Envelhecimento acelerado & $42 \mathrm{~b}$ & $54 \mathrm{~b}$ & 7,3 \\
\hline C.V. (\%) & $54 \mathrm{a}$ & $75 \mathrm{a}$ & 6,9 \\
\hline
\end{tabular}

${ }^{1}$ Médias seguidas da mesma letra nas colunas não diferem entre si pelo teste de Tukey a 5\%.

Pelos resultados do vigor de sementes, avaliado pelo teste de tetrazólio e de envelhecimento acelerado (Tabela 1) observa-se que, para os lotes 1,2 e 3, a imersão das sementes em água por 60 minutos, para retirar o tegumento, seguida de mais 60 minutos de imersão em água, para retirar a membrana, classificou as sementes quanto ao vigor de forma similar à efetuada pelo teste de envelhecimento acelerado. Para o lote 2, classificação semelhante também foi obtida quando as sementes foram imersas em água por 60 ou 30 minutos, para retirar o tegumento e por 30 minutos, para retirar a membrana que cobre o embrião.

Em sementes hidratadas por 30 minutos, o tegumento ainda estava aderido e a sua remoção causava injúrias ao embrião; assim, durante a avaliação esses danos foram considerados e os resultados obtidos indicaram que a avaliação do vigor das sementes dos três lotes testados não estava correta.

De modo geral, a combinação mais eficiente para a realização do teste de tetrazólio visando avaliar a viabilidade e o vigor foi a hidratação das sementes por 60 minutos para remoção do tegumento e mais 60 minutos de imersão em água para a remoção da membrana, mantendo os embriões em solução de tetrazólio a $0,075 \%$ a $40{ }^{\circ} \mathrm{C}$ por 60 minutos. 
TABELA 2. Viabilidade e vigor de sementes de pepino avaliados pelos testes de tetrazólio (TZ viab. e TZ vigor), germinação (G.), envelhecimento acelerado com solução salina (EASS) e emergência da plântula (EP), lotes 1, 2, 3, 4, 5 e 6 cultivar Safira e lotes 7, 8, 9, 10, 11 e 12, cultivar Jóia.

\begin{tabular}{|c|c|c|c|c|c|c|}
\hline Cultivar & Lote & TZ viab. & G. & TZ vigor & EASS & EP \\
\hline \multirow{7}{*}{ Safira } & \multicolumn{6}{|c|}{ 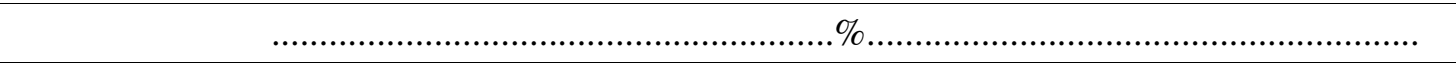 } \\
\hline & 1 & $99 a^{1}$ & 98 a & $91 \mathrm{a}$ & 97 a & 96 a \\
\hline & 2 & 99 a & $100 \mathrm{a}$ & $90 \mathrm{a}$ & $95 \mathrm{ab}$ & 99 a \\
\hline & 3 & 98 a & 98 a & $87 \mathrm{ab}$ & $86 \mathrm{bc}$ & 95 a \\
\hline & 4 & 99 a & 99 a & $81 \mathrm{ab}$ & $82 \mathrm{c}$ & 99 a \\
\hline & 5 & $92 \mathrm{~b}$ & $100 \mathrm{a}$ & $31 \mathrm{c}$ & $23 \mathrm{~d}$ & $100 \mathrm{a}$ \\
\hline & 6 & $97 \mathrm{ab}$ & 99 a & $76 \mathrm{~b}$ & $85 \mathrm{bc}$ & $97 \mathrm{a}$ \\
\hline C.V (\%). & & 2,7 & 2,0 & 7,4 & 6,3 & 3,1 \\
\hline \multirow{6}{*}{ Jóia } & 7 & $98 \mathrm{ab}$ & 99 a & $90 \mathrm{a}$ & $86 \mathrm{a}$ & $100 \mathrm{a}$ \\
\hline & 8 & $96 \mathrm{ab}$ & 96 a & $88 \mathrm{a}$ & $82 \mathrm{a}$ & $96 \mathrm{ab}$ \\
\hline & 9 & $94 \mathrm{~b}$ & $94 \mathrm{a}$ & $81 \mathrm{ab}$ & $79 \mathrm{a}$ & $90 \mathrm{~b}$ \\
\hline & 10 & $96 \mathrm{ab}$ & 99 a & $16 \mathrm{c}$ & $12 \mathrm{c}$ & $98 \mathrm{ab}$ \\
\hline & 11 & 99 a & 95 a & $73 \mathrm{~b}$ & $63 \mathrm{~b}$ & $98 \mathrm{ab}$ \\
\hline & 12 & $97 \mathrm{ab}$ & $94 \mathrm{a}$ & $73 \mathrm{~b}$ & $82 \mathrm{a}$ & $91 \mathrm{~b}$ \\
\hline C.V (\%). & & 2,3 & 4,1 & 9,0 & 8,1 & 3,7 \\
\hline
\end{tabular}

${ }^{1}$ Médias seguidas da mesma letra na coluna, não diferem entre si pelo teste de Tukey a 5\%.

Os resultados da viabilidade e do vigor das sementes de 12 lotes, avaliados pelos testes de tetrazólio, de germinação, de emergência de plântulas e de envelhecimento acelerado estão na Tabela 2. O teste de germinação não detectou diferenças entre os 6 lotes do cv. Safira, enquanto a avaliação da viabilidade pelo teste de tetrazólio indicou o lote 5 como o de menor viabilidade, diferindo dos outros lotes, com exceção do 6. Nota-se que as porcentagens de viabilidade pelo teste de tetrazólio variaram de 92 a 99 e pelo teste de germinação essa variação foi de 98 a 100. Assim, o teste de tetrazólio produziu resultados coerentes com os obtidos pelo teste de germinação, com valores próximos, embora o teste de comparação de médias aplicado tenha indicado diferença estatística entre alguns desses valores.

Resultado semelhante foi verificado para os 6 lotes do cv. Jóia (Tabela 2), tanto pelos resultados do teste de tetrazólio como pelos de germinação; a viabilidade dos lotes variou de 94 a $99 \%$, porém a análise estatística indicou algumas diferenças entre lotes pelo teste de tetrazólio, mas, tendo em vista a proximidade numérica dos valores, essas diferenças são irrelevantes. Barros (2002) também verificou a associação entre os resultados de germinação e os de viabilidade pelo teste de tetrazólio em sementes de abóbora e abobrinha.
Comparando a avaliação do vigor pelos testes de tetrazólio e de envelhecimento acelerado, observa-se que houve coerência entre os resultados para as sementes dos dois cultivares (Tabela 2). Resultado semelhante foi observado por Barros et al. (2005) na avaliação do vigor de sementes de abobrinha pelos testes de tetrazólio e de envelhecimento acelerado. Assim, o teste de tetrazólio indicou os lotes 5 e 10 como os de menor vigor, mesma classificação do teste de envelhecimento acelerado. Quanto à definição dos lotes de maior vigor, para o cv. Safira, o teste de tetrazólio indicou os lotes 1 e 2 como superiores e estatisticamente iguais aos lotes 3 e 4, enquanto o teste de envelhecimento acelerado indicou a superioridade do lote 1 em relação aos lotes 3,4 , 5 e 6 .

Para o cv. Jóia, os testes de tetrazólio e de envelhecimento acelerado indicaram o lote 10 como o de menor vigor e os lotes 7, 8 e 9 como os de maior vigor. Apenas para o lote 12 não foi verificada similaridade entre os resultados dos dois testes. Santos et al. (2007) obtiveram também resultados adequados decorrentes da avaliação do vigor de sementes de tomate pelo teste de tetrazólio.

$O$ teste de emergência das plântulas não foi sensível para detectar diferenças de vigor entre os lotes; as condições 
em que o teste foi conduzido, principalmente com relação à temperatura e à quantidade de água, foram ideais para a espécie avaliada e, por isso, os resultados foram similares aos do teste de germinação. Em sementes de abobrinha, Barros (2002) observou que o teste de emergência de plântulas foi o único que não diferenciou os lotes em diferentes níveis de vigor.

Com base nessas condições, é possível estimar a viabilidade e o vigor de sementes de pepino, com redução significativa do tempo de preparo das sementes em relação ao estabelecido nas regras para análise de sementes.

\section{CONCLUSÃO}

O teste de tetrazólio é eficiente para avaliar a viabilidade e o vigor das sementes de pepino. Para a condução do teste, as sementes secas devem ser cortadas no lado oposto ao do eixo embrionário, imersas em água a $40^{\circ} \mathrm{C}$ por 60 minutos, para a retirada do tegumento, e por mais 60 minutos a 40 ${ }^{\circ} \mathrm{C}$, para a remoção da membrana interna e, em seguida, imersas em solução de tetrazólio $0,075 \%$, a $40^{\circ} \mathrm{C}$, por 60 minutos.

\section{REFERÊNCIAS}

ASSOCIATION OF OFFICIAL SEED ANALYSTS AOSA. Seed vigor testing handbook. Wageningen: AOSA. 1983, 88p. (Contribuition, 32).

BARROS, A.C.S. Testes para avaliação rápida da viabilidade e do vigor de sementes de soja. 1988, 140f. Dissertação (Mestrado em Fitotecnia) - Escola Superior de Agricultura Luiz de Queiroz - Universidade de São Paulo, Piracicaba, 1988.

BARROS, D.I. Teste de tetrazólio para a avaliação da qualidade fisiológica de sementes de abóbora e abobrinha. 2002, 62f. Dissertação (Mestrado em Fitotecnia) - Universidade Federal de Viçosa, Viçosa, 2002.

BARROS, D.I.; DIAS, D.C.F.S.; BHERING, M.C. Uso do teste de tetrazólio para avaliação da qualidade de sementes de abobrinha. Revista Brasileira de Sementes, v.27, n.2, p.165-171, 2005.

BHERING, M.C.; DIAS, D.C.F.S.; BARROS, D.I. Adequação da metodologia do teste de tetrazólio para avaliação da qualidade de sementes de melancia. Revista Brasileira de Sementes, v.27, n.1, p.176-182, 2005.

BHERING, M.C.; SILVA, R.F.; ALVARENGA, E.M.; DIAS, D.C.F.S. Metodologia do teste de tetrazólio em sementes de feijão. In: KRZYZANOWSKI, F.C.; VIEIRA,
R.D.; FRANÇA NETO, J.B. Vigor de sementes: conceitos e testes. Londrina: ABRATES. Cap 8.3, p.1-10, 1999.

BHERING, M.C.; SILVA, R.F.; ALVARENGA, E.M.; DIAS, D.C.F.S.; PENA, M.F. Avaliação da viabilidade e do vigor de sementes de feijão-de-vagem (Phaseolus vulgaris L.) pelo teste de tetrazólio. Viçosa: Universidade Federal de Viçosa, Boletim Técnico, 1996, 27p.

BITTENCOURT, S.R.M. de; VIEIRA, R.D. Metodologia do teste de tetrazólio em sementes de amendoim. In: KRZYZANOWSKI, F.C.; VIEIRA, R.D.; FRANÇA NETO, J.B. Vigor de sementes: conceitos e testes. Londrina: ABRATES. Cap 8.2, p.1-8, 1999.

BRASIL. Ministério da Agricultura e Reforma Agrária. Secretaria Nacional de Defesa Agropecuária. Departamento Nacional de Produção Vegetal. Coordenação de Laboratório Vegetal. Regras para Análise de Sementes. Brasília, DF, 1992. 365p.

CARVALHO, N.M.; TOLEDO, F.F. Determinação da germinação de sementes de capim colonião (Panicum maximum Jacq) através do uso do tetrazólio. I - Proposição de um método de trabalho. Científica, v.4, n.2, p.185-190, 1976.

CHAMMA, H.M.C.P.; NOVEMBRE, A.D.L.C. Teste de tetrazólio para as sementes de milho: períodos de hidratação e de coloração das sementes. Revista Brasileira de Sementes, v.29, n.2, p.125-129, 2007.

COSTA, N.P.; MARCOS FILHO, J. Alternative methodology for the tetrazolium test for soybean seeds. Seed Science and Technology, v.22, n.1, p.9-17, 1994.

COSTA, N.P.; FRANÇA NETO, J.B.; KRZYZANOWSKI, F.C.; HENNING, A.A. Avaliação da metodologia alternativa para o teste de tetrazólio para sementes de soja. Scientia Agrícola, v.55, n.2, p.305-312, 1998.

COSTA, N.P.; MARCOS FILHO, J; FRANÇA NETO, J.B.; KRZYZANOWSKI, F.C.; HENNING, A.A. Teste de tetrazólio em sementes de soja com pré condicionamento abreviado - Série Sementes. Londrina: Embrapa- CNPSo. 2008, 7p. (Embrapa Soja. Circular Técnica, 56).

DIAS, M.C.L.L.; ALVES, S.J. Avaliação da viabilidade de sementes de Brachiaria brizantha (Hoscst. Ex A. Rich) Stapf pelo teste de tetrazólio. Informativo ABRATES, v.11, n.2, p.317, 2001.

DIAS, M.C.L.L.; BARROS, A.S.R. Avaliação da qualidade de sementes de milho. Londrina: Instituto Agronômico do Paraná. 1995, 43p. (IAPAR. Circular, 88).

FRANÇA NETO, J.B.; KRZYZANOWSKI, F.C.; COSTA, N.P. Metodologia do teste de tetrazólio em sementes de soja. In: KRZYZANOWSKI, F.C.; VIEIRA, R.D.; 
FRANÇA NETO, J.B. Vigor de sementes: conceitos e testes. Londrina: ABRATES. Cap 8.5, p.1-27, 1999.

FRANÇA NETO, J.B.; PEREIRA, L.A.G.; COSTA, N.P.; KRZYZANOWSKI, F.C.; HENNING, A.A. Metodologia do teste de tetrazólio em sementes de soja. Londrina: EMBRAPA- CNPSo. 1988, 60p. (Série Documento, 32).

LIMA, L.B de; MARCOS FILHO, J. Vigour tests in cucumber seeds. In: ISTA Congress, 28, 2007, Foz do Iguaçu. Seed Symposium Abstracts, 2007, v.28, p.144.

MARCOS FILHO, J. Fisiologia de sementes de plantas cultivadas. Piracicaba: Fealq, 2005, 495p.

MOORE, R.P. Interpretation of color differences in tetrazolium testing. Seed Technologist News, v.44, n.3, p.22-24, 1972.
NOVEMBRE, A.D.L.C.; CHAMMA, H.M.C.P.; GOMES, R.B.R. Viabilidade das sementes de braquiária pelo teste de tetrazólio. Revista Brasileira de Sementes, v.28, n.2, p.147-151, 2006.

SANTOS, M.A.O.; NOVEMBRE, A.D.L.C.; MARCOS FILHO, J. Tetrazolium test to assess viability and vigour of tomato seeds. Seed Science and Technology, v.35, n.1, p.213-223, 2007.

VIEIRA, M.G.G.C.; VON PINHO, E.V.R. Metodologia do teste de tetrazólio em sementes de algodão. In: KRZYZANOWSKI, F.C.; VIEIRA, R.D.; FRANÇA NETO, J.B. Vigor de sementes: conceitos e testes. Londrina: ABRATES. Cap 8, p.1-13, 1999. 